\title{
Effect of Compressor Outlet Pressure on Liquefaction and Refrigeration Capacity
}

\author{
Nishigandha Patel ${ }^{*}$, Supriya Gambhire ${ }^{\dagger}$, Chetan Waykole ${ }^{\dagger}$ and Mangesh Saraf ${ }^{\dagger}$ \\ ${ }^{\dagger}$ Mechanical Department, MITCOE, Pune, India
}

Accepted 02 March 2016, Available online 15 March 2016, Special Issue-4 (March 2016)

\begin{abstract}
The main components of a helium liquefier which determines the performance of the HRL for a given compressor flow rate are Turbine, Heat exchanger and JT valve. Turbine and JT valve produces cooling effect of helium gas by isentropic and isenthalpic expansion process respectively. Different components can be made to have different thermodynamic cycle configuration. For each configuration main components can have different operating process parameters leading to different performance of HRL. This project involves the analysis and optimization of these process parameters for a given configuration. This analysis and optimization work will also involve different practical factors and in efficiencies of main components.
\end{abstract}

Keywords: Liquefaction, Helium, process parameters, Optimization, Turbine, heat exchanger.

\section{Introduction}

Helium liquefier as the name suggest is used for the liquefaction process of Helium gas. The cold box shown below is used for the cool down and liquefaction purpose of Helium gas coming out of the Tokomak. Cold box contains total 8 heat exchangers and 3 turbines which expand isentropically and one JT valve which expands isenthalpically. Process parameters of heat exchanger are effectiveness or UA, mass flow rate, Temperatures and for turbine are temperatures, mass flow rate, inlet outlet pressure; efficiency has to be optimized to get maximum liquefaction of LHe with minimum refrigeration load.

Normally JT valve is kept at the lowest temperature followed by the performance of other components and hence optimization of its process parameter is not considered here. One of the optimum cycle configurations is provided here that gives the higher cooling effect with a lower capital investment and operating cost of different HRL components. This configuration has three turbines and eight heat exchangers which produces liquid helium at $4.5 \mathrm{~K} .1^{\text {st }}$ and $2^{\text {nd }}$ turbines operates at warmer temperature compared to $3^{\text {rd }}$ turbine which has process flow paths connected in series. Helium stream coming out of the $1^{\text {st }}$ turbine passes to the heat exchanger which will reduce its temperature before entering the $2^{\text {nd }}$ turbine. Helium mass flow rate supplied by the compressor system is $140 \mathrm{~g} / \mathrm{s}$ at pressure of 14 bars and $310 \mathrm{k}$ temperature. A part of this mass flow rate passes

*Corresponding author: Nishigandha Patel through a $1^{\text {st }}$ and $2^{\text {nd }}$ turbine for isentropic expansion and then this low pressure helium stream comes back to compressor suction through different heat exchangers to transfer cooling effect to the hot stream coming from the compressor. $3^{\text {rd }}$ turbine will expand the remaining part of the main helium stream will further passes through a heat exchanger before entering the JT valve for liquid helium production.

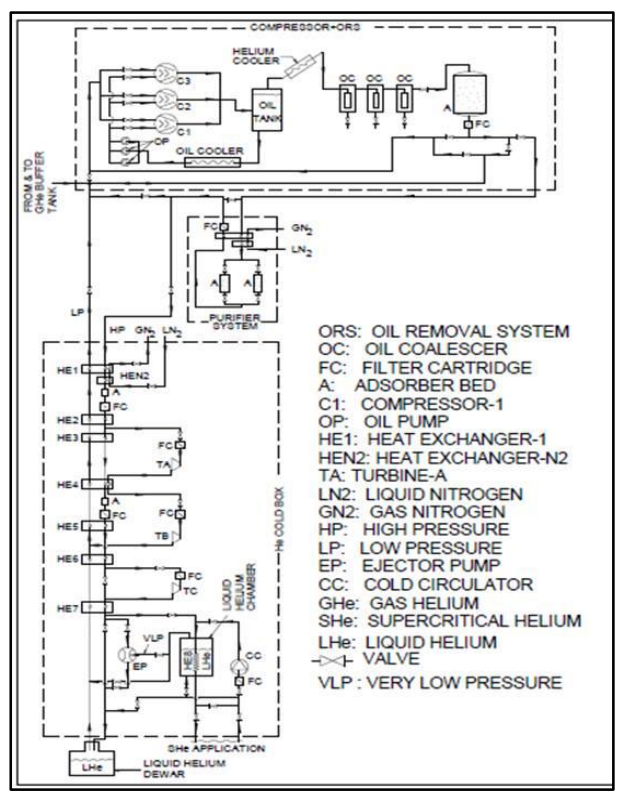

Figure 1.1 Typical Schematic of the cold box along with the warm and cold end components for Helium plant of Tokamak 


\section{Effect of Compressor Outlet Pressure on Liquefaction and Refrigeration Capacity}

Developed procedure for 2 compressors, $140.7 \mathrm{~g} / \mathrm{s}$ is at compressor outlet pressure of 14 bar. At different compressor outlet pressures liquid formation at JT outlet and refrigeration capacity is calculated and tabulated below. Graph of liquid formation at JT outlet and refrigeration capacity against compressor outlet pressure has been plotted below which shows that both liquid formation and refrigeration capacity increases as compressor outlet pressure is increasing.

Table 2.1: Liquid formation at JT outlet, Refrigeration capacity and JT inlet temperature at different compressor outlet pressure for 2 compressor system with $3^{\text {rd }}$ turbine

\begin{tabular}{|c|c|c|c|}
\hline $\begin{array}{c}\text { Pressure } \\
\mathrm{Pa}\end{array}$ & $\begin{array}{c}\text { JT Inlet } \\
\mathrm{k}\end{array}$ & $\begin{array}{c}\text { liquefaction } \\
\mathrm{g} / \mathrm{s}\end{array}$ & $\begin{array}{c}\text { Refrigeration load } \\
\mathrm{W}\end{array}$ \\
\hline & & & \\
1200000 & 5.761282527 & 29.33742534 & 436.55 \\
1400000 & 5.255432267 & 42.91480427 & 701.90 \\
1600000 & 4.885541404 & 49.2079059 & 824.89 \\
1800000 & 4.687424143 & 52.03264347 & 880.10 \\
2000000 & 4.583452649 & 53.40708397 & 906.96 \\
2200000 & 4.525941217 & 54.13970546 & 921.28 \\
\hline & & & \\
\hline
\end{tabular}

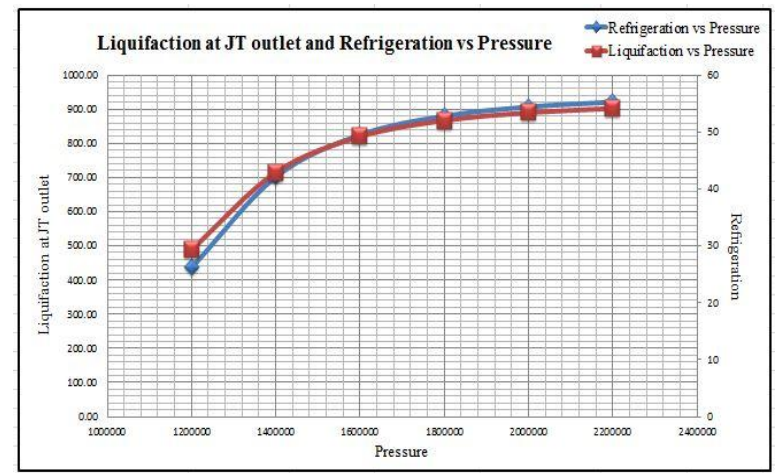

Figure 2.1: Liquid formation at JT outlet, Refrigeration capacity VS pressure for 2 compressor system with $3^{\text {rd }}$ turbine

\section{Validation Using Aspen Hysys}

\subsection{Process Flow Diagram of Helium Liquefier in Aspen Hysys}

Figure shows the process flow diagram that drawn in Hysys. Table shows the steady state properties of all the streams in the PFD, material stream 49 gives the helium liquefaction rate

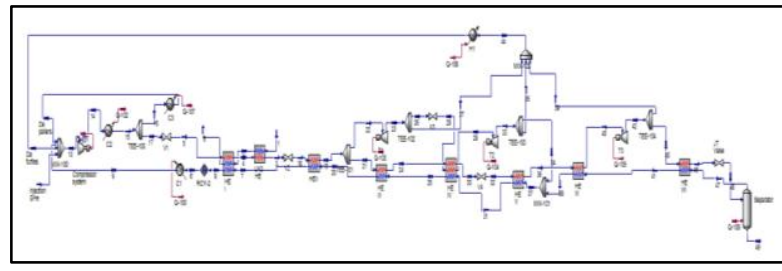

Figure 3.1.1: PFD of Helium Liquefier

\subsection{Material Streams}

Table 3.2.1: Material streams in Helium Liquefier

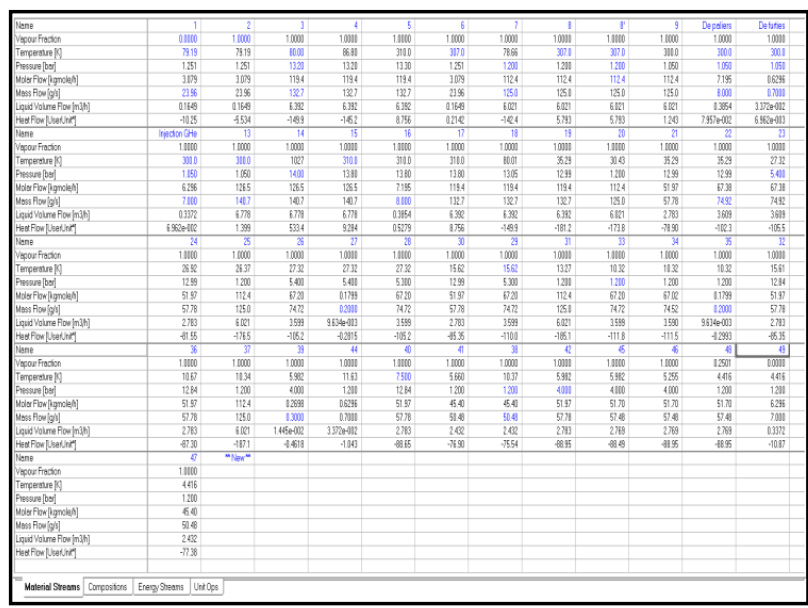

\section{Conclusion}

Among all analyzed methods steady state approach is effectively used for the optimization of process parameters of turbine and heat exchanger such as mass flow rate, temperature, inlet outlet turbine pressures, effectiveness or UA.

Analytically developed procedure for 2 compressors has been validated using Aspen HYSYS. Optimization of process parameters like compressor outlet pressure is done using analytical method which comes out to be 14 bar.

\section{References}

Barron, R.F., Cryogenic systems Oxford University Press (1985)

Flynn, T.M., Cryogenic Engineering Marcel Dekker (1977)

Trougott, H.K., Yuan, S.W.K., Cryogenics-Low Temperature Engineering and Applied Science (1986

Ventura, G., Risegari, L., The Art of Cryogenics, Low-temperature experimental Elsevier (2008)

Richard, T. Jacobsen, Steven, G.Penoncello and Eric, W.Lemmon, Thermodynamic Properties of Cryogenic Fluid Plenum Press

Van Sciver, S.W., Helium cryogenics Plenum Press, New York, USA, 1986

Atrey, M.D., Thermodynamic analysis of Collins helium liquefaction cycle Cryogenics, Cryogenics Section, Centre for Advanced Technology, Indore 452 013, India (1998)

Seidu, S.O (2008). Influence of Inoculant's type on thermal analysis parameters

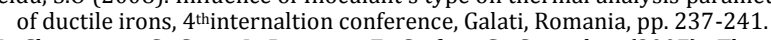

M. Chisamera, S. Stan, I. Riposan, E. Stefan, G. Costache, (2007), Thermal analysis of Inoculated Grey Cast Irons,U GALMAT, Galati, Technologiisi MaterialeAvansate ,University press,Vol.1, pp.17-23. 